\title{
The role of leukocytes in tissue injury
}

\author{
E. Crockett-Torabi and P. A. Ward \\ Department of Pathology, The University of Michigan Medical School, Ann Arbor, Michigan 48109-0602, USA
}

\section{E. Crockett-Torabi and P. A. Ward (1996) European J ournal of Anaesthesiology, 13, 235-246 The role of leukocytes in tissue injury}

\section{Summary}

The recruitment of leukocytes to the sites of inflammation and leukocyte-derived inflammatory mediators contributes to the development of tissue injury associated with inflammatory diseases. The first step in the pathogenesis of inflammatory conditions is adhesion of circulating leukocytes to activated vascular endothelial cell in the inflamed tissues and subsequent transmigration through the endothelial cells. During these processes, leukocytes are activated to secrete a variety of substances such as growth factors, chemokines and cytokines, complement components, proteases, nitric oxide, and reactive oxygen metabolites, which are considered to be one of the primary sources of the tissue injury. Prevention or reduction of leukocyte-endothelial cell adhesion often results in a profound attenuation of the microvasculature and parenchymal cell dysfunction in various animal models of human inflammatory diseases. It has been shown that all aspirin-like non-steroidal anti-inflammatory agents share at least one characteristic in that all of these agents diminish the adhesive interactions required for the accumulation of leukocytes at the site of inflamed tissue. The challenge for future investigations will need to be carefully examined: the relations between leukocyte and endothelial cell interactions, the mechanisms of activation of leukocytes and endothelial cells, and the components of the signaling pathways. Information related to these topics will allow a better understanding of the role of leukocytes in inflammatory tissue injury and the development of novel therapeutic strategies.

Keywords: Leukocytes, adhesion molecules, tissue injury, inflammation, inflammatory mediators

\section{Introduction}

While acute inflammation has a normal role in host defence and tissue repair, an unregulated or chronic cycle of inflammation can lead to excessive tissue injury and disease. Tissue injury may result from either direct effects of the pathological agent or as a consequence of an inflammatory cell influx. Phagocytic cells including circulating neutrophils and monocytes, and tissue macrophages play a key role in inflammatory responses.

When pathogenic agents are formed or deposited in host tissues, circulating neutrophils and/or monocytes may be recruited from the intravascular compartment to the site of insult by the local generation of soluble mediators. The recruitment of circulating neutrophils/ monocytes from blood into sites of tissue injury is a

Correspondence: E. Crockett-Torabi. crucial component of the inflammatory response which involves a highly regulated series of cellular responses and the local production of inflammatory mediators including chemotactic factors, vasoactive agents, cytokines, lysosomal enzymes, as well as the production of toxic oxygen metabolites. Recruitment of the neutrophils/monocytes into tissues is initiated by adherence of circulating leukocytes to activated endothelial cells in the inflamed tissues, and subsequent transmigration through the endothelial cells. Adhesion and migration is not a random process and is orchestrated by specific adhesion molecule receptors and counter receptors expressed on leukocytes, endothelial cells, and defined regions of extracellular matrix and coagulation proteins. It has become clear that the recruitment and activation of leukocytes are regulated by a complex network of interactions between adhesion molecules, cytokines, and other inflammatory mediators. In this article we 
will review the mechanisms that regulate leukocyte (in particular neutrophils) recruitment and their relation to the development of inflammatory responses and tissue injury. We will focus on the activation of neutrophils as a general model of phagocyte activation. Although there are specific differences in the biochemical processes associated with stimulation of each inflammatory cell type, dependent on the stimulus and extent of cell differentiation, there are several common themes that are associated with inflammatory cell activation.

\section{Leukocytes and inflammatory tissue injury}

Numerous studies have demonstrated the critical role of phagocytic cells in the pathogenesis of tissue injury seen in inflammatory diseases, ischaemia-reperfusion, septic shock, stroke, and organ transplantation. These observations are largely the result of studies of experimental animal models under conditions of neutropenia or in which monoclonal antibodies directed against phagocytes and endothelial adhesion molecules were applied. These studies have shown that prevention or reduction of phagocyte-endothelial cell adhesion often results in a profound attentuation of the microvasculature and parenchymal cell dysfunction seen in various animal models of human disease [1-2]. One of the primary sources of the tissue injury is attributed to the secretory products of activated phagocytes including reactive oxygen metabolites, and lysosomal enzymes[3-6]. The mechanisms involved in the regulation of neutrophil/monocyteendothelial cell interactions and subsequent tissue injury occurring during inflammation are complex and can occur at several stages: (a) recognition of inflammatory stimuli through cell surface receptors, (b) cell activation through the generation of intracellular membrane, and (c) delivery of inflammatory mediators to the site of infection or inflammation. In this review, we will highlight some of the recent advances in each of these areas as a basis for a better understanding of the regulation of the inflammatory response.

\section{Cell activation}

One of the early stages of acute inflammation results from the ability of circulating neutrophils/monocytes to recognize chemoattractants, adhere to the vascular endothelium and migrate along the chemoattractant gradient (i.e. chemotaxis) through capillary endothelium into the tissue [7-9]. During these processes, phagocytes are activated to secrete a variety of substances such as growth factors and cytokines inducing recruitment of other inflammatory cells and mesenchymal cells [10-12].

Chemoattractants interact with specific receptors on the cell surface. Neutrophils and monocytes can be stimulated with different chemoattracants including bacteria derived $\mathrm{N}$-formyl peptides, complement component $\mathrm{C} 5 \mathrm{a}$, leukotriene B4, platelet activating factor (PAF), and a variety of cytokines [11-16]. In addition, bacterial lipopolysaccharide is one of the most potent activators of phagocytic cells. The interaction of any of these stimuli with specific receptors on cell surface activates the cell resulting in a variety of functional responses such as generation of cytokines and chemokines, increases in adherence capacities of the cell, directional migration of the cell, phagocytosis of particles, generation of oxygen metabolites, exocytosis of cytoplasmic granules, and a variety of intermediary biochemical reactions $[8,17,18]$. The molecular signaling mechanisms of phagocyte activation are not within the scope of this review and readers are referred to other reports [19-22].

\section{Role of oxygen products}

Binding of appropriate stimuli to cell-surface receptors of phagocyte leads to increased consumption of oxygen concomitant with the formation and secretion of superoxide anion $\left(\mathrm{O}_{2}^{-}\right)$by a plasma membrane associated, $\mathrm{NADPH}$-dependent oxidase [23]. $\mathrm{O}^{-}{ }_{2}$ may be further reduced to hydrogen peroxide $\left(\mathrm{H}_{2} \mathrm{O}_{2}\right)$. Subsequent reaction of $\mathrm{O}^{-}{ }_{2}$ and $\mathrm{H}_{2} \mathrm{O}_{2}$ in the presence of $\mathrm{a}$ transition metal ion and specific peroxidases results in the formation of secondary oxygen metabolites (i.e. hydroxyl radical, singlet oxygen, hypochlorous acid and chloramines). Hydrogen peroxide and $\mathrm{O}^{-}{ }_{2}$ can react with some biological targets, whereas hydroxyl radical and specially hypochlorous acid demonstrate broad reactivity toward biomolecules. The oxygen metabolites not only can initiate cytotoxic injury, but can also directly alter the biochemical and biophysical properties of structural proteins of tissues, including elastin and collagen, as well as mucopolysaccharides. Because of the potential toxicity of oxygen radicals, 
cells can eliminate $\mathrm{O}^{-}$and $\mathrm{H}_{2} \mathrm{O}_{2}$, thereby limiting formation of hydroxyl radicals. The mechanisms for elimination include specific enzyme scavengers including superoxide dismutase (SOD) for $\mathrm{O}^{-}$and peroxidases and catalase for $\mathrm{H}_{2} \mathrm{O}_{2}$. Preventing metal ions from redox cycling is an alternative mechanism for inhibition of hydroxyl radical formation. The spectrum of oxidant species generated during phagocyte stimulation is highly variable depending on the cell type. The nature of the phagocyte, the stimulus, its secretory products, the target cell, and the extracellular environment can modulate the type and magnitude of oxidants generated [23].

Abundant evidence implicates a pathogenic role for oxygen metabolites in mediating tissue injury in vivo and in vitro [4,24-27]. In vitro studies have shown that interaction of rat pulmonary endothelial cells and phorbol ester activated human neutrophils resulted in endothelial cell injury and death in a time-dependent and cell-dependent (ratio of neutrophils to endothelial cells) [28]. The cell injury is attributed to toxic oxygen products from neutrophils since catalase protected endothelial cells death, and neutrophils from patients with chronic granulomatous disease (can not generate an effective respiratory burst) induced little or no endothelial injury. In contrast, catalase exhibited no protective effect when microvascular endothelial cells from human omentum were used. However, chlormethyl ketone inhibitors which inactivate the catalytic site in elastase inhibited the endothelial cell injury suggesting the role of a non oxygen radical-dependent mechanism. These studies suggest that the cytotoxic effects of activated neutrophils on the vascular endothelium may result from the combined effects of oxygen products and proteases released from the neutrophil.

Reperfusion of ischaemic myocardium promotes an influx of neutrophils which injure the myocardium [29]. The adherence of neutrophils to myocytes activates the neutrophils respiratory burst resulting in a highly compartmental iron-dependent myocyte oxidative injury [30,3]. A recent study demonstrated a significant increase in myocardial $\mathrm{H}_{2} \mathrm{O}_{2}$ during the ischaemic phase and a much larger increase within minutes of reperfusion of rat heart [32]. Furthermore, it has been shown that the formation of oxidative metabolites play a critical role in the development of hepatocellular injury following hepatic ischaemia/reperfusion. Although the process is complex it appears that generation of both tumour necrosis factor (TNF) and the reactive oxygen metabolites contribute to hepatocellular injury following hepatic ischaemia/reperfusion [26].

\section{Role of nitric oxide}

Nitric oxide, a short-lived, highly reactive gas generated by lightning and pollution, is also generated by mammalian and other eukaryotic cells [33-35]. Dissolved in the aqueous cellular fluid, it diffuses through membranes, and is so reactive that it disappears within moments of its production. In the living organism, nitric oxide synthase oxidizes L-arginine to L-citrulline and nitric oxide. There are two general forms of nitric oxide synthases: constitutive and inducible isoforms. The latter enzyme, which is found in phagocytic cells, can be induced by a variety of immunological or inflammatory stimuli including endotoxins or cytokines [34]. Superoxide reacts with nitric oxide generating peroxynitrite $\left(\mathrm{ONOO}^{-}\right)$which can further give rise to hydroxyl radical through a novel mechanism (i.e. $\mathrm{ONOO}^{-}+\mathrm{H}^{+} \rightarrow \mathrm{ONOOH} \rightarrow \mathrm{HO} \cdot+\mathrm{NO}_{2} \cdot$ ) that is not dependent on a redox active transition metal ion [36]. Nitric oxide is involved in the regulation of the cardiovascular, central, and peripheral nervous systems, as well as in other homeostatic mechanisms [34]. Several lines of evidence implicate nitric oxide as an endogenous inhibitor of leukocyte adhesion in venules [37]. It has been shown that nitric oxide promotes the ADP ribosylation of actin in human neutrophil, which is associated with reversible inhibition of F-actin polymerization and the inhibition of neutrophil adhesion to a fibronectin-coated surface [38].

Studies suggest that the induction of nitric oxide synthase may contribute to chronic inflammatory disease. An enhanced level of nitric oxide, citrulline, or nitrite has been shown in patients with asthma [39], ulcerative colitis [40], and arthritis [41]. An increased expression of inducible oxide synthase or its mRNA has also been demonstrated in microglial cells and brain tissue after viral infection [42], treatment with cytokines [43], or in experimental encephalitis [42]. Treatment with inhibitors of nitric oxide synthase reduces inflammation and tissue injury in animal models of acute inflammation or arthritis [44,45], and prevents the development of arthritis and inflammatory 
nephritis in mice with spontaneous autoimmune disease [46]. Inhibitors of nitric oxide synthase reduce immune complex-induced tissue injury in rat lungs and dermal vasculature [47]. Exogenous and endogenous sources of nitric oxide can limit the degree of endothelial activation and inhibit monocyte adhesion which may contribute to some of its antiatherogenic and antiinflammatory properties within the vessel wall [48].

The pathophysiological consequences of enhanced nitric oxide production are not yet known. However, it appears that nitric oxide has both a protective and deleterious effects as suggested by different experimental models of shock, ischaemic reperfusion in the brain and heart, and pulmonary inflammatory conditions [39,49-50]. Studies have shown different responses to inhibitors of nitric oxide production when human cell (i.e. macrophage) is compared with animal cell (i.e. mouse macrophage) indicating the need to consider experimental conditions and species in the interpretation of the results [51]. Modulation of nitric oxide is a major focus of anti-inflammatory research and its therapeutic potential is under intensive investigation. A number of recent articles cover the biochemical and molecular mechanisms, and therapeutic strategies related to nitric oxide [34,39,51-54].

\section{Role of complement}

Although the complementsystem provides a rapid and efficient means of killing invading micro-organisms, its inappropriate activation and excess production may contribute to tissue injury in many diseases. Complement plays an important role in the pathophysiology of inflammatory responses, particularly through the release of several active biological fragments such as $\mathrm{C} 3 a, \mathrm{C} 5 \mathrm{a}, \mathrm{C} 3 \mathrm{~b}$, and $\mathrm{sC} 5 \mathrm{~b}-9$, which are generated during its activation [55]. C5a is capable of amplifying the inflammatory responses via its chemoattractant properties, its induction of granule release in phagocytic cells, and its ability to induce phagocyte generation of oxygen metabolites $[56,57]$. Complement components are not only derived from circulation, but are also synthesized locally which may be important in the protection of tissues against inflammation and infection or may contribute to tissue injury. Neutrophils store C3, C7, and C6 which can be released under specific stimulatory conditions [58]. Monocytes and macrophages produce all components of the terminal complement pathway. In vitro cell culture have shown that human mesengial cells can synthesize $\mathrm{C} 4$ and factor $\mathrm{B}$, and astroglioma cell lines synthesize components of both the classical and alternative pathways $[55,59,60]$.

Human cells are protected from complement by membrane proteins which inibit activation and its effects at several stages of the pathway [61]. These include: decay-accelerating factor (DAF; CD55), membrane cofactor protein (MCP; CD46), complement receptor 1 (CR1; CD35), and CD59. These proteins, which are widely expressed and are particularly abundant in cells and fluids of the reproductive system, maintain homeostasis by preventing uncontrolled activation of complement in tissues. Some of these molecules have been cloned and expression of soluble forms of these regulatory proteins (e.g. SCR1; soluble complement receptor 1 ) has raised the prospect of their use in therapy. Intravenous infusion of sCR1 which blocks complement activation of both pathways has been shown to have significant protective effects in models of lung and dermal vascular injury in rat [62]. The protective effects were associated with reduction in neutrophil recruitment suggesting the implication of adhesion molecules in these processes. Promising results from animal models of myocardial infarction, cardiopulmonary bypass, limb and gut ischaemia, thermal injury, transplantation, and demyelination have been reported [61]. Preliminary human studies indicated that SCR1 is nontoxic and of low (or absent) immunogenecity. Clinical trials are in progress in the adult respiratory distress syndrome (ARDS), an acute diffuse inflammatory reaction in lung with multiple aetiologies which if the patient survives the acute episode may result in marked lung fibrosis. Experimental studies suggest that in many cases, the initiation of ARDS is part mediated by neutrophil dependent lung endothelial cell injury [63]

\section{Role of chemokines}

Chemokines (chemotactic cytokines) are small proinflammatory peptides (ranging from 6 to $15 \mathrm{kd}$ ) that are best known for their leukocyte chemoattractant activity $[17,64]$. These chemoattractants are subdivided into two distinct supergene families, C-X-C ( $\alpha$ chemokine) and $C-C$ ( $\beta$-chemokine), according to the position of the first two cysteine amino acid residues. 
In vitro chemotaxis assays show that the $\mathrm{C}-\mathrm{X}-\mathrm{C}$ family of chemokines tend to attract neutrophils and 11 of them have been identified (e.g. IL-8, platelet factor 4 , platelet basic protein cleavage products). The C-C family of chemokines act preferentially on monocytes/ macrophages, lymphocytes, and eosinophils. The C$\mathrm{C}$ family are comprised of at least seven closely related proteins: monocyte chemoattractant protein (MCP)-1, 2 , and -3 , macrophage inflammatory protein-1 $\alpha$ (MIP$1 \alpha$ ) and $-1 \beta$, RANTES, and I-309. In addition, a third type of chemokine (C) has recently been identified. The only example at present is lymphotactin, which is specific for $T$ cells [65].

Numerous studies have demonstrated the expression of these proteins or the elevation of their mRNAs in a diverse array of conditions marked by recruitment of leukocytes. There appears to be a strong correlation with the expression of chemokines and inflammatory diseases including atherosclerosis [66-68], psoriasis [69], infectious disease [70], glomerular injury [71], rheumatoid arthritis [68], ischaemia-reperfusion injury [68], and pulmonary and allergic airway inflammation[72-74]. Recent studies using animal models have demonstrated more direct proof for the critical role of chemokines in inflammatory processes and tissue injury by the application of antibodies to chemokines. Administration of neutralizing antibody against IL-8 in several types of acute inflammatory reactions in rabbits (including LPS-induced dermatitis, LPS/IL-1 induced arthritis, ischaemia/reperfusion lung injury and immune complex-type glomerulonephritis) have prevented neutrophil infiltration and tissue injury [75]. Similar protective effects of antibody against IL-8 were observed in reversed passive Arthus reactions induced by intradermal injection of anti-BSA and intravenous infusion of BSA. IL-8 also inhibited exudation of neutrophils into the peritoneal cavity in response to glycogen [76]. However, anti-IL-8 antibody did not protect neutrophil-mediated injury of the pulmonary vasculature induced by intravascular activation of complement by cobra venom factor [76]. In addition, anti-IL-8 did not protect pulmonary injury induced by deposition of IgA, since monocytes and macrophages play a key role in this condition. A monoclonal antibody homologue to $\mathrm{C}-\mathrm{C}$ chemokine MCP-1 reduced accumulation of mononuclear phagocytes, vascular leakage, and haemorrhage by more than $50 \%$ in this study [77]. Similarly, in a rat model of mononuclear phagocyte-dependent granuloma, intravenous and intratracheal administration of anti-rat MIP-1 antibody reduced the number and size of granulomas formed in lungs infused with glucan particles [78]. These studies collectively indicate that $\mathrm{C}-\mathrm{X}-\mathrm{C}$ chemokine IL-8 plays a key role in certain types of inflammatory conditions which are neutrophil dependent, whereas C-C chemokines play a critical role in mononuclear phagocyte-dependent inflammatory tissue injury.

In vivo the activity of chemokines is regulated by several potential mechanisms including: (a) down regulation of their expression by anti-inflammatory cytokines (e.g. IL-4, IL-10), (b) neutralization of chemokines activity by autoantibodies (e.g. anti-IL-8, anti-MIP), (c) scavenging of free chemokines by cell surface receptors (e.g. receptor on red cell identical to Duffy antigen), and (d) inhibition of responses to chemokines by chemokines themselves (e.g., IL-8, MIP-1)[64]. These mechanisms are considered as promising targets for the development of anti-inflammatory therapies.

\section{Role of cytokines}

Cytokines are a heterogeneous group of polypeptides which orchestrate the complex network of cellular interactions that regulate immune response to antigen and mediate various aspects of inflammation, immunity, and vascular injury [79]. Although T cells, natural killer cells and mononuclear phagocytes are the main source of cytokines, a number of studies have demonstrated that other cells such as neutrophils, epithelial, and endothelial cells also have the ability to synthesize and release immunoregulatory cytokines [80-83]. It has been shown that neutrophils can release TNF- $\alpha, \mathrm{IL}-\beta, \mathrm{IL}=1$ ra (IL-1 receptor antagonist), IL-8, and TGF- $\beta 1$ (transforming growth factor $\beta 1$ ) [80]. The molecular mechanisms of cytokine action are not within the scope of this article and readers are referred to other reports [84-86].

Numerous studies indicate that cytokines play a key role in the pathogenesis of inflammatory tissue injury associated with the rejection of transplanted organs [87], pulmonary granuloma and fibrosis [74, 88-90], septic shock[91], psoriasis and other inflammatory skin conditions [92-93], ischaemia-reperfusion injury [94], allergic airway inflammation [73], glomerulonephritis [95], arthritis [96], organ- 
specific autoimmune diseases [97], endotoxin [98] and immune-complex-induced diseases [4,89,99-101]. Tumour necrosis factor has been implicated in many of these disease conditions [102]. Substantial amounts of TNF have been detected in broncho alveolar lavage fluid from the lung model of immune-complex induced injury and in serum of patients in septic shock [100, 103]. Injection of purified recombinant TNF into experimental animals has resulted in a dose-dependent altered pathophysiology and organ injury [102,104].

In different experimental animal models, injection of neutralizing antibody to TNF reduced the lethality observed following injection of endotoxin [102,105], and the intensity of lung injury induced by the immune complex [4]. It has been shown that the production of TNF along with the participation of phagocytes, plays an important role in tissue injury. In a lung model of immune complex induced tissue injury the protective effects of anti-TNF antibody was related to a significantly diminished influx of neutrophils into the lung parenchyma [4]. An animal model of ischaemia/ reperfusion injury to liver has shown that although the TNF production is important other factors such as neutrophils may contribute to part of the liver injury $[94,106]$. Other studies indicate that in endotoxin-induced liver injury, hepatic macrophages and TNF played a crucial role in liver injury [98]. It has been suggested that TNF may enhance the recruitment of phagocytes into tissue injury sites by modulating the adhesion molecules which play a crucial role in adherence of leukocytes to endothelial cells and their migration through the endothelial cells. TNF as well as IL-1 stimulate increased adhesivity of endothelial cells in culture for neutrophils, eosinophils, basophils, and monocytes $[19,82,107]$. These effects of IL-1 and TNF are blocked by RNA and protein synthesis inhibitors [107].

In as much as cytokines amplify and perpetuate the inflammatory reactions and contribute to the associated tissue injury, their synthesis should be regulated to resolve the inflammatory response and reestablish homeostasis. Recent studies have shown that certain lipid and protein mediators of inflammatory response have regulatory activity. Prostaglandin E2, TGF- $\beta$, IL-4, IL-10, and IL-1ra have all been shown to prevent specific cytokine expression and also exhibit anti-inflammatory effects [108-110]. It has been shown that endogenously produced IL-10 is a natural suppressant of the cutaneous inflammatory responses [110]. Other studies have shown that in IgG immune-complex-induced acute lung injury the intrinsic IL-10 plays an important regulatory role in the inflammatory response [108]. Anti-IL-10 antibody increased the level of TNF- $\alpha$ in bronchoalveolar lavage which is consistent with endogenous IL-10 having the ability to suppress the production of cytokines such as TNF- $\alpha$, IL-1, and IFN- $\gamma$ in vitro [111]. As mentioned above, TNF has the ability to modulate the phagocyteendothelial interactions and their recruitment. Recently, it has been shown that a matrix metalloproteinase (MMP)-like enzyme is a critical component of TNF- $\alpha$ processing, and that the inhibitors of MMP prevented the rise in blood level of TNF and were effective in animal models of inflammatory disease such as adjuvant arthritis [112]. Pharmacological therapies take advantage of these regulatory molecules for intervening in the production of cytokines. Cytokine-binding proteins, such as soluble cytokine receptors and monoclonal antibodies are agents of considerable therapeutic potential in this regard [113].

\section{Role of proteases and other inflammatory proteins}

The inflammatory processes are modulated by a number of different cellular and plasma enzymes including serine proteases, metalloproteases, cationic proteins, acid hydrolases, myeloperoxidase, and lactoferrin. Recent experimental evidence has suggested that proteases, in addition to their role in cellular cytotoxicity, can influence monocyte motility and chemotaxis, modulate cytokine responses, contribute to mononuclear cell proliferation, or induce target cell apoptosis [6]. Serine proteases are stored in secretory granules of neutrophils, cytolytic $T$ lymphocytes and natural killer cells. The neutrophil granular serine proteases (i.e. cathepsin G, elastase, proteinase-3) can directly degrade vascular basement membrane in vitro and are thought to play an important role in mediating tissue injury in a number of disease states and inflammatory conditions. Thrombin, urokinase-type plasminogen activator and factor $\mathrm{Xa}$ are plasma proteases. Thrombin, in addition to its role in leukocyte growth control, exerts a potent proinflammatory effect through its modulation of leukocyte chemotaxis and adherence properties. It has been shown that thrombin 
in addition to its direct effect (i.e. chemoattractant) on leukocyte migration, may regulate leukocyte migration through direct modulation of gene expression and cytokine release[114-115]. Similarly, it has been shown that urokinase stimulated leukocyte migration in an in vivo mouse model. In addition, urokinase plays a crucial role in tissue remodeling through its ability to degrade matrix proteins, laminin and fibronectin and to activate latent matrix metalloproteinases and collagenases [6]. The role of factor $X$ relevant to tissue injury is attributed to its ability to bind vascular endothelial cells inducing release of platelet-derived growth factor-like molecules.

Metalloproteinases (e.g. collagenase, gelatinase) are a family of zinc- and calcium-dependent endopeptidases that are active in the degradation of extracellular matrix. Neutrophil metalloproteinases are localized in the secretory granules and are released secondary to lysosomal degranulation at inflammatory sites. Studies have shown that matrix metalloproteinase- 9 derived from macrophages can solubilize the elastin of the mature elastic fibres in the arterial wall [117]. The activity of metalloproteinase is regulated by plasma proteins including $\alpha_{2}$-macroglobulin and cell-derived tissue inhibitors of metalloproteinases (i.e. TIMP-1 and TIMP-2) [118].

A cationic antimicrobial protein (CAP37) has been isolated from neutrophil granules released during inflammation. In addition to its bacterial role, CAP37 is implicated in inflammation because of its effect on the recruitment and activation of monocytes as well as its effect on endothelial cells and fibroblasts [119]. Lactoferrin, a multifunctional immunoregulatory protein, is another inflammatory mediator which exhibits antimicrobial properties [120]. Lactoferrin is an ironbinding protein which is found in external secretions, such as breast milk, and in the secondary granules of neutrophils. Lactoferrin can affect various immunological functions, including antibody synthesis in vitro, production of IL-1, IL-2, and TNF- $\alpha$, natural killer-cell cytotoxicity, complement activation, and lymphocyte proliferation. In addition, lactoferrin binds to LPS and thereby decreases the production of LPS-mediated TNF- $\alpha$ production.

\section{Role of adhesion molecules}

The recruitment of circulating leukocytes into tissues is the cellular hallmark of acute inflammation. This multistep event is initiated by adherence of circulating leukocytes to activated vascular endothelial cells in the inflamed tissues, and subsequent transmigration through the endothelial cells. The interaction of leukocytes with vascular endothelial cells is a primary event that involves participation of distinct families of adhesion molecules including the integrins, selectins, and certain members of an immunoglobulin superfamily known as intercellular adhesion molecules (ICAMS) [19]. The selectin family of adhesion molecules (i.e. L-, E-, and P-selectin) and their carbohydrate containing counter receptors mediate the initial interaction of leukocytes (i.e. rolling) with the vascular endothelium [116]. Subsequent leukocyte adhesive events, including transendothelial migration and cell interactions with the extracellular matrix are mediated by integrins and members of ICAMs. Leukocytes express $\beta 2$-integrins (Mac- 1 , LFA- 1 , and p150, 90 ), and selectin (L-selectin) on their surfaces. Leukocyte and endothelial integrins, in conjunction with other members of ICAMs and selectins function together during vasculogenesis, angiogenesis, inflammation, and wound healing [121]. The leukocyte adhesion molecules are important components of cellular signal transduction $[116,122]$. The mechanisms of signal transduction and the regulation of adhesion molecules are not within the scope of this article and readers are referred to other sources [19, 116,122-123].

The adhesion molecules, ICAM- 1 and $\beta 2$-integrins, are essential for leukocyte migration into sites of inflammation. Monoclonal antibodies to Mac-1 molecules or to their endothelial counter receptor, ICAM-1, blocks neutrophil adherence and extravasation in vivo[19]. A low number of Mac-1 molecules are expressed on the unactivated neutrophil surface and are up-regulated and become functionally active upon neutrophil stimulation. The avidity of $\beta 2-$ integrins for their ligands can be regulated by cellular activation. Although ICAM-1 is constitutively present on endothelial cells, its expression can be augmented by a variety of inflammatory mediators including TNF, IL- $1, \gamma$-interferon, and endotoxin. In addition, these cytokines can induce upregulation of E-selectin on endothelial cells [19,37].

Numerous studies have provided evidence indicating that leukocyte-endothelial adhesion plays a 
crucial role in the recruitment of leukocytes into sites of tissue injury and the pathogenesis of inflammation [124-126]. In rats with nephrotoxic nephritis the simultaneous administration of antibodies to ICMA- 1 and LFA- 1 prevented the development of proteinuria, the influx of inflammatory cells into the glomerular capillary tuft, and the subsequent crescent formation [126]. Other studies demonstrated that antibodies to $\beta 2$-integrins (CD18), and to E-selectin (endothelial leukocyte adhesion molecule, ELAM) exhibited potent anti-inflammatory effects, resulting in a striking amelioration of injury in experimental phacoanaphylactic endophthalmitis in rats [127]. ICAM-1 has been shown to play a significant role in the hepatic ischaemia/reperfusion neutrophil-dependent phase of the injury [128]. Adherence dependent on Mac-1 and ICAM-1 has been shown to activate the neutrophil respiratory burst resulting in cardiac myocyte injury $[31,122]$. Other studies have shown that interruption of selectin-mediated neutrophil adherence with soluble sialyl Lewis oligosaccharide following ischaemia/reperfusion on the rabbit ear resulted in significant reduction in tissue injury[129]. Another experimental animal model of inflammatory tissue injury suggested a compartmentalized role for adhesion molecules in lung inflammatory tissue injury following intra-alveolar deposition of IgG immune complexes [101]. Neutrophil inhibitory factor that binds Mac- 1 and inhibits Mac-1-dependent neutrophil adhesion prevented neutrophil-dependent lung vascular injury by inhibiting neutrophil adhesion to the TNF- $\alpha$-activated endothelium [130]. All these studies collectively underscore the roles of adhesion molecules and the complexity of leukocyte-endothelial interactions in inflammatory tissue injury. It must be mentioned that there are other factors, such as the extracellular matrix proteins, which play a crucial role in leukocyte-endothelial cells and readers are referred to a recent review related to this subject [131].

Interruption of the leukocyte-endothelial cell cascade has been a major focus of anti-inflammatory research and its therapeutic potential is under intense investigation. It has been shown that all Aspirin-like nonsteroidal anti-inflammatory agents that are often used share at least one characteristic: all of these agents diminish the adhesive interactions required for the accumulation of leukocytes at the site of inflamed tissue $[37,131]$.

\section{Conclusions}

The recruitment of leukocytes to the sites of inflammation and leukocyte-derived inflammatory mediators, such as chemokines, complement components, proteases, nitric oxide, and reactive oxygen metabolites contribute to the development of tissue injury associated with a variety of disease states including asthma, emphysema, myocardial infarction, adult respiratory distress syndrome, glomerulonephritis, immune complex-mediated vasculitis, and rheumatoid arthritis. The first step in the pathogenesis of these inflammatory conditions is adhesion of leukocytes to and transmigration across the vascular endothelium. Both leukocytes and endothelial cells play an active role in this process by regulating the expression and conformational changes of adhesion molecules that mediate adhesion. Through the signaling properties of highly regulated membrane receptors, adhesion molecules influence inflammatory responses. The production of inflammatory mediators can further modulate leukocyte-endothelial interactions and thereby contribute to more complex interactions and the development of tissue injury. The challenge for future investigations will be to dissect and identify structure-function requirements of adhesion molecules-cellular interactions and their regulation by the inflammatory mediators, and to elucidate the intracellular signaling mechanisms regulating these interactions. A better understanding of the cellular and molecular mechanisms of inflammatory disease processes will assist in finding new approaches to the development of therapeutic interventions.

\section{Acknowledgments}

We are grateful to $\mathrm{Dr}$ J oseph C. Fantone of the Department at The University of Michigan for his critical evaluations of the manuscript. We thank Brent Sullenbarger for assistance in preparation of the manuscript. This work was supported in part by $\mathrm{NIH}-$ 1 R29 Al31443 grant and the American Heart Association of Michigan 63GB956 grant.

\section{References}

1 Korthuis RJ , Anderson DC, Granger DN. Role of neutrophil endothelial cell adhesion in inflammatory disorders. J Crit Care 1994; 9: 1-26. 
2 Lehr HA, Menger MD, Mersmer K. Impact of leukocyte adhesion on myocardial ischemia/reperfusion injury: conceivable mechanisms and proven facts. J Lab Clin Med 1993; 121: 539-545.

3 Fantone J C, Feltner De, Brieland J L, Ward PA. Phagocytic cell derived inflammatory mediators and lung disease. Chest 1987; 91: 428-435.

4 Ward PA, Warren J S, Varani J, J ohnson KJ. PAF, cytokines, toxic oxygen products and cell injury. Molec Aspects Med 1991; 12: 169-174.

5 Smith J A. Neutrophils, host defense, and inflammation: a double edge sword. J Leuk Biol 1994; 56: 672-686.

6 Altieri DC. Proteases and protease receptors in modulation of leukocyte effector functions. J Leuk Biol 1995; 58: $120-127$.

7 Baggiolini M. Activation and recruitment of neutrophil leukocyte. Clin Exp Immunol 1995; 101 suppl 1: 5-6.

8 Cochrane CG. Mechanisms coupling stimulation and function in leukocytes. Fed Proc Nat Acad Sci 1984; 43: 2729-2731.

9 Smith CW. Transendothelial migration. In: Harlan J M, Liv DY, eds. Adhesion: Its Role in Inflammatory Disease. New York: Freeman, 1992: 63-98.

10 Kiritsy $C P$, Lynch $A B$, Lynch SE. Role of growth factors in cutaneous wound healing: a review. Crit Rev Oral Biol 1993; 4: 729-760.

11 Deuel TF, Senior RM, Huang J S, Griffin GL. Chemotaxis of monocytes and neutrophils to platelet derived growth factor. J Clin Invest 1982; 69: 1054-1064.

12 Drake WT, Isseckutz AC. Transforming growth factor Beta 1 enhances polymorphonuclear leukocyte accumulation in dermal inflammation and transendothelial migration by priming action. Immunol 1993; 78: 197-204.

13 Garner WL, Rodriguez J L, Miller J M et al. Acute skin injury releases neutrophil chemoattractants. Surgery 1994; 116: 42-48.

14 Siegbahn A, Hammacher A, Westermark B, Heldin CH. Differential effects of the various isoforms of plateletderived growth factor on chemotaxis of fibroblasts, monocytes, and granulocytes. J Clin Invest 1990; 85: 916-920.

15 Cavaillon J M. Cytokines and macrophages. Biomed Pharmacol 1994; 48: 445-453.

16 Unemori EN, Ferrara N, Baver EA, Amento VP. Vascular endothelial growth factor induces interstitial collegenase expression in human endothelial cells. J Cell Physiol 1992; 153: 557-562.

17 Ahuja SK, Gao J i-L, Murphy PM. Chemokine receptors and molecular mimicry. Immunol Today 1994; 15: 281287.

18 Schall TJ. The cytokines. In: Thomson AW, ed. The Cytokine Handbook. London: Academic Press. 1994: 419-460.

19 Crockett-Torabi E, Fantone J C. Signal transduction and adhesion molecules. In: Ward PA, Fantone J C, eds. Adhesion Molecules and the Lung. New York: Marcel Dekker, Inc. 1996. (In press.)

20 Reiner NE. Altered cell signaling and mononuclear phagocyte deactivation during intracellular infection. Immunol Today 1994; 15: 374-381.

21 Hallett MB, Lloyds D. Neutrophil priming: the cellular signals that say 'amber' but not 'green'. Immunol Today 1995; 16: 264-268.

22 Edwards SW, Watson F. The cell biology of phagocytes. Immunol Today 1995; 16: 508-510.

23 Rosen GM, Pou S, Ramos CL, Cohen MS, Britigan BE. Free radicals and phagocytic cells. FASEB J 1995; 9: 200-209.

24 Fantone J C, Ward PA. Role of oxygen derived free radicals and metabolites, in leukocyte dependent inflammation reactions. Am J Pathol 1982; 107: 397-418.

25 Lucchesi BR, Werns SW, Fantone J C. The role of the neutrophil and free radical in ischemia myocardial injury. J Mol Cell Cardiol 1989; 21: 1241-1251.

26 Scales WE, Campbell J r DA, Green ME, Remick DG. Hepatic ischemia/reperfusion injury: importance of oxidant/tumor necrosis factor interactions. Am J Physiol 1994; 267: G1122-G1127.

27 Spector RA. Oxidative stress induced cataract: mechanisms of action. FASEBJ 1995; 9: 1173-1182.

28 Ward PA, Varani J. Mechanisms of neutrophil-mediated killing of endothelial cells. J Leukoc Biol 1990; 48: 97-102.

29 Dreyer WJ , Michael LH, West MS et al. Neutrophil accumulation in ischemic canine myocardium. Insights into time course, distribution, and mechanism of localization during early reperfusion. Circulation 1991; 84: 400-411.

30 Mullane KM, Smith CW. The role of leukocytes in ischemic damage, reperfusion injury and repair of the myocardium. In: Piper HM, ed. Pathophysiology of Severe Ischemic Myocardial Injury. Dordrecht: Kluwer Academic Publishers, 1990: 239-267.

31 Entman ML, Youker K, Shoji T et al. Neutrophil induced oxidative injury of cardiac myocytes. A compartmented system requiring CD11b/CD18-ICAM-1 adherence. J Clin Invest 1992; 90: 1335-1345.

32 Slezak J , Tribulova N, Pristacova J et al. Hydrogen peroxide changes in ischemic and reperfused heart. Cytochemistry and biochemical and X-ray microanalysis. Am J Pathol 1995; 147: 772-781.

33 Nathan C, Xie QW. Regulation of biosynthesis of nitric oxide. J Biol Chem 1994; 269: 13725-13728.

34 Moncada S, Higgs EA. Molecular mechanisms and therapeutic strategies related to nitric oxide. FASEB J 1995; 9: 1319-1330.

35 Stevens C. Is nitric oxide the "retrograde messenger"? Science 1991; 254: 1296-1297.

36 Beckman J S, Beckman TW, Chen J , Marshall PA, Freeman 
BA. Apparent hydroxyl radical production by peroxynitrite: implications for endothelial injury from nitric oxide and superoxide. Proc Natl Acad Sci USA 1990; 87: 1620-1624.

37 Granger DN, Kubes P. The microcirculation and inflammation: modulation of leukocyte-endothelial cell adhesion. J Leukoc Biol 1994; 55: 662-675.

38 Clancy R, Leszczynska J, Amin A, Levartovsky D, Abramson SB. Nitric oxide stimulates ADP ribosylation of actin in association with the inhibition of actin polymerization in human neutrophils. J Leukoc Biol 1995; 38: 196-202.

39 Barnes PJ, Liew FY. Nitric oxide and asthmatic inflammation. Immunol Today 1995; 16: 128-130.

40 Boughton-Smith NK, Evans SM, Hawkey CJ et al. Nitric oxide synthase activity in ulcerative colitis and Crohn's disease. Lancet 1993; 342: 338-340.

41 Farrell AJ, Blake DR, Palmer RM, Moncada S. Increased concentrations of nitrite in synovial fluid and serum samples suggest increased nitric oxide synthesis in rheumatic diseases. Ann Rheum Dis 1992; 51: 1219-1222.

42 Koprowski $\mathrm{H}$, Zheng YM, Heber-Katz $\mathrm{E}$ et al. In vivo expression of inducible nitric oxide synthase in experimentally induced neurologic diseases (published erratum appears in Proc Natl Acad Sci USA 1993; 90: 5378) Proc Natl Acad Sci USA 1993; 90: 3024-3027.

43 Boje KM, Arora PK. Microglial-produced nitric oxide and reactive nitrogen oxides mediate neuronal cell death. Brain Res 1992; 587: 250-256.

44 lalenti A, lanaro A, Moncada S, Di Rosa M. Modulation of acute inflammation by endogenous nitric oxide. Eur J Pharmacol 1992; 211: 177-182.

45 McCartney-Francis N, Allen J B, Mizel DE et al. Suppression of arthritis by an inhibitor of nitric oxide synthase. J Exp Med 1993; 178: 749-754.

46 Weinberger J B, Granger DL, Pisetsky DS et al. The role of nitric oxide in the pathogenesis of spontaneous murine autoimmune disease: increased nitric oxide production and nitric oxide synthase expression in MRL-1pr/1pr mice, and reduction of spontaneous glomerulonephritis and arthritis by orally administered NG-monomethyl-Larginine. J Exp Med 1994; 179: 651-660.

47 Mulligan MS, Hevel J M, Marletta MA, Ward PA. Tissue injury caused by deposition of immune complexes is Larginine dependent. Proc Natl Acad Sci USA 1991; 88: 6338-6342.

48 DeCaterina R, Libby P, Peng H-B et al. Nitric oxide decreases cytokine-induced endothelial activation. Nitric oxide selectively reduces endothelial expression of adhesion molecules and proinflammatory cytokines. J Clin Invest 1995; 96: 60-68.

49 Tsuji M, Dimov VB, Yoshida T. In vivo expression of monokine and inducible nitric oxide synthase in experimentally induced pulmonary granulomatous inflammation. Evidence of sequential production of interleukin-1 inducible nitric oxide synthase and tumor necrosis factor. Am J Path 1995; 147: 1001-1015.

50 MoncadaS, Higgs A. The L-arginine-nitric oxide pathway. N Engl J Med 1993; 329: 2002-2012.

51 Murray HW, Teitelbaum RF. L-arginine-dependent reactive nitrogen intermediates and the antimicrobial effect of activated human mononuclear phagocytes. J Infect Dis 1992; 155: 513-517.

52 Maeda H, Akaike T, Yoshida M, Suga M. Multiple functions of nitric oxide in pathophysiology and microbiology: analysis by a new nitric oxide scavenger. J Leuk Biol 1994; 56: 588-592.

53 Salvemini D, Manning PT, Zweifel BS etal. Dual inhibition of nitric oxide and prostaglandin production contributes to the antiinflammatory properties of nitric oxide synthase inhibitors. J Clin Invest 1995; 96: 301-308.

54 Xie Q, Nathan C. The high-output nitric oxide pathway: role and regulation. J Leukoc Biol 1994; 56: 576-582.

55 Pascual M, French LE. Complement in human diseases: looking towards the 21st century. Immunol Today 1995; 16: $58-61$.

56 Webster RO, Hong SR, J ohnston J r RB, Henson PM. Biological effects of the human complement fragments $\mathrm{C5a}$ and C5ades Arg on neutrophil function. Immunopharmacology 1980; 2: 201-219.

57 Frank MM. Complement in the pathophysiology of human disease. N Engl J Med 1987; 316: 1525-1530.

58 Myrvang Hogasen AK, Wurzner R, Abrahamsen TG, Dierich MP. Human polymorphonuclear leukocytes store large amounts of terminal complement components C7 and 66 which may be released on stimulation. J Immunol 1995; 154: 4734-4740.

59 Gasque P, Fontaine M, Morgan BP. Complement expression in human glial cells and cell lines. J Immunol 1995; 154: 4726-4733.

60 Gasque P, Chan P, Fontaine $M$ et al. Identification and characterization of the complement $\mathrm{C} 5 \mathrm{a}$ anaphylatoxin receptor on human astrocytes. J Immunol 1995; 155: 4882-4889.

61 Morgan BP. Complement regulatory molecules: application to therapy and transplantation. Immunol Today 1995; 16: 257-259.

62 Mulligan MS, Yeh CG, Rudolph AR, Ward PA. Protective effects of soluble CR1 in complement- and neutrophilmediated tissue injury. J Immunol 1992; 148: 1479-1485.

63 Zimmerman GA, Renzetti AD, Hill HR. Functional and metabolic activity of granulocytes from patients with adult respiratory distress syndrome. Am Rev Respir Dis 1983; 127: 290-300.

64 Furie MB, Randolph GJ. Chemokines and tissue injury review. Am J Path 1995; 146: 1287-1301.

65 Kennedy J , Kelner GS, Kleyensteuber S et al. Molecular cloning and functional characterization of human lymphotactin. J Immunol 1995; 155: 203-209. 
66 Schwartz CJ , Valente AJ, Sprague EA. A modern view of atherogenesis. Am J Cardiol 1993; 71: 9B-14B.

67 Edgington SM. Chemokines in cardiovascular disease: do chemoattractant cytokines regulate the progression of atherosclerosis? Biol Technol 1993; 11: 676-679.

68 Strieter RM, Koch AE, Antony VB, Fick J r RB, Standiford TJ , Kunkel SL. The immunopathology of chemotactic cytokines: the role of interleukin-8 and monocyte chemoattractant protein-1. J Lab Clin Med 1994; 123: 183-197.

69 Schroder J M. Peptides and cytokines. Arch Dermatol Res 1992; 284 Suppl 1: S22-S26.

70 Kunkel SL, Lukacs NW, Strieter RM. The role of interleukin-8 in the infectious process. Ann NY Acad Sci 1994; 730: 134-143.

71 Schlondorff D. Potential role of chemotactic cytokines in glomerular injury. Clin Invest 1993; 71: 815-816.

72 Driscoll KE. Macrophage inflammatory proteins: biology and role in pulmonary inflammation. Exp Lung Res 194; 20: 473-490.

73 Lukacs NW, Strieter RM, Kunkel SL. Leukocyte infiltration in Allergic Airway Inflammation. Am J Respir Cell Mol Biol 1995; 13: 1-6.

74 Smith RE, Strieter RM, Zhang $\mathrm{K}$ et al. A role of C-C chemokines in fibrotic lung disease. J Leukoc Biol 1995; 57: 782-787.

75 Harada A, Sekido N, Akahoshi T, Wada T, Mukaida N, Matsushima K. Essential involvement of interleukin-8 (IL-8) in acute inflammation. J Leukoc Biol 1994; 56: 559-564.

76 Mulligan MS, J ones ML, Bolanowski MA et al. Inhibition of lung inflammatory reactions in rats by an anti-human IL-8 antibody. J Immunol 1993; 150: 5585-5595.

77 J ones ML, Mulligan MS, Flory CM, Ward PA, Warren J S. Potential role of monocyte chemoattractant protein $1 / \mathrm{J} E$ in monocyte/macrophage-dependent IgA immune complex alveolitis in the rat. J Immunol 1992; 149: 2147-2154.

78 Flory CM, J ones ML, Warren J S. Pulmonary granuloma formation in the rat is partially dependent on monocyte chemoattractant protein 1. Lab Invest 1993; 69: 396-404.

79 Vilcek J, Le J, Le J . Immunology of cytokines: an introduction. In: Thomson AW, ed. The Cytokine Handbook. London: Academic Press, 1991: 1-17.

80 Cassatella MA. The production of cytokines by polymorphonuclear neutrophils. Immunol Today 1995; 16: 21-26.

81 Stadnyk AW. Cytokine production by epithelial cells. FASEB J 1994; 8: 1041-1047.

82 Cotran RS, Pober J S. Cytokine-endothelial interactions in inflammation, immunity, and vascular injury. J Am Soc Nephrol 1990; 1: 225-235.

83 Young HA, Hardy KJ . Role of interferon-gamma immune cell regulation. J Leuk Biol 1995; 58: 373-381.

84 Oppenheim J J. Summary of the fifth conference on the molecular mechanisms and physiological activities of cytokines. J Leukoc Biol 1994; 56: 687-691.

85 Taga T, Kishimoto T. Signaling mechanisms through cytokine receptors that share signal transducing receptor components. Curr Opin Immunol 1995; 7: 17-23.

86 Larrick J W, Wright SC. Cytotoxic mechanism of tumor necrosis factor-alpha. FASEB J 1990; 4: 3215-3223.

87 Maury CP, Teppo AM. Raised serum levels of cachectin/ tumor necrosis factor alpha in renal allograft rejection. J Exp Med 1987; 166: 1132-1127.

88 Flory CM, J ones ML, Miller BF, Warren J S. Regulatory roles of tumor necrosis factor-a and interleukin-1-B in monocyte chemoattractant protein-1-mediated pulmonary granuloma formation in the rat. AmJ Path 1995; 146: $450-462$.

89 Warren J S. Intrapulmonary interleukin 1 mediates acute immune complex alveolitis in the rat. Biochem Biophys Res Commun 1991; 175: 604-610.

90 Lukacs NW, Chensue SW, Strieter RM, Warmington K, Kunkel SL. Inflammatory granuloma formation is mediated by TNF-alpha-inducible intercellular adhesion molecule-1. J Immunol 1994; 152: 5883-5889.

91 Remick DG. Cytokines and septic shock. Bailliere's Clinical Infectious Diseases. 1994; 1: 37-50.

92 Nickoloff B. Cytokine Networks; immunobiology surfaces proposed cytokine interactions in psoriasis. J NIH Res 1991; 3: 71-74.

93 Moulin V. Growth factors in skin wound healing. Europ J Cell Biol 1995; 68: 1-7.

94 Remick DG, Colletti LM, Scales WA, McCurry KR, Campbell J r DA. Cytokines and extrahepatic sequelae of ischemia-reperfusion injury to the liver. Ann NY Acad Sci 1994; 723: 271-283.

95 Remick DG. Significance of in vivo detection of tumor necrosis factor (editorial; comment). Lab Invest 1991; 65: 259-261.

96 Saxne T, Palladino J r MA, Heinegard D, Talal N, Wollheim FA. Detection of tumor necrosis factor alpha but not tumor necrosis factor beta in rheumatoid arthritis synovial fluid and serum. Arthritis Rheum 1988; 31: 10411045.

97 Trembleau S, Germann T, Gately MK, Adorini L. The role of IL-12 in the induction of organ-specific autoimmune diseases. Immunol Today 1995; 16: 383-386.

98 Fujita S, Arii S, Moden et al. Participation of hepatic macrophages and plasma factors in endotoxin-induced liver injury. J Surgical Res 1995; 59: 263-270.

99 Mulligan MS, Ward PA. Immune complex-induced lung and dermal vascular injury. Differing requirements for tumor necrosis factor-alpha and IL-1. J Immunol 1992; 149: 331-339.

100 Warren J S, Yabroff KR, Remick DG et al. Tumor necrosis factor participates in the pathogenesis of acute immune 
complex alveolitis in the rat. J Clin Invest 1989; 84: 1873-1882.

101 Mulligan MS, Vaporciyan AA, Warner RL et al. Compartmentalized roles for leukocytic adhesion molecules in lung inflammatory injury. J Immonl 1995; 154: 13501363.

102 Remick DG, Kunkel SL. Pathophysiologic alterations induced by tumor necrosis factor. Int Rev Exp Pathol 199; 34 Pt B: 7-25.

103 Waage $A$. Production and clearance of tumor necrosis factor in rats exposed to endotoxin and dexamethasone. Clin Immunol Immunopathol 1987; 45: 348-355.

104 Tracy KJ, Beutler B, Lowry SF et al. Shock and tissue injury induced by recombinant human cachectin. Science 1986; 234: 470-474.

105 Beutler B, Krochin N, Milsark IW, Luedke C, Cerami A. Control of cachectin (tumor necrosis factor) synthesis: mechanisms of endotoxin resistance. Science 1986; 232: 977-980.

106 Langdale LA, Flaherty LC, Liggitt HD, Harlan J M, Rice CL, Winn RK. Neutrophils contribute to hepatic ischemiareperfusion injury by a $C D$ 18-independent mechanism. J Leukoc Biol 1993; 53: 511-517.

107 Bevilacqua MP, Pober J S, Wheeler ME, Cotran RS, Gimbrone J r MA. Interleukin 1 acts on cultured human vascular endothelium to increase the adhesion of polymorphonuclear leukocytes, monocytes, and related leukocyte cell lines. J Clin Invest 1985; 76: 2003-2011.

108 Shanley TP, Schmal H, Friedl HP, J ones ML, Ward PA. Regulatory effects of intrinsic IL-10 in IgG immune complex-inducted lung injury. J Immunol 1995; 154: 34543460.

109 Van Hal PT, Hopstaken-Broos J P, Prins A et al. Potential indirect anti-inflammatory effects of IL-4. Stimulation of human monocytes, macrophages, and endothelial cells by IL-4 increases aminopeptidase-N activity (CD13; EC 3.4.11.2). J Immunol 1994; 153: 2718-2728.

110 Berg DJ, Leach MW, Kuhn R et al. Interleukin 10 but not interleukin 4 is a natural suppressant of cutaneous inflammatory responses. J Exp Med 1995; 182: 99-108.

111 Bogdan C, Nathan C. Modulation of macrophage function by transforming growth factor beta, interleukin-4, and interleukin-10. Ann NY Acad Sci 1993; 685: 713-739.

112 Gearing AJ, Beckett P, Christodoulou M et al. Matrix metalloproteinases and processing of pro-TNF-alpha. J Leukoc Biol 1995; 57: 774-777.

113 Klein B, Brailly H. Cytokine-binding proteins: stimulating antagonists. Immunol Today 1995; 16: 216-219.

114 Bar-Shavit R, Kahn A, Wilner GD, Fenton J W. Monocyte chemotaxis: stimulation by specific exosite region in thrombin. Science 1983; 220: 728-731.
115 Zimmerman GA, Mclntyre TM, Prescott SM. Thrombin stimulates the adherence of neutrophils to human endothelial cells in vitro. J Clin Invest 1985; 76: 2235-2246.

116 Crockett-Torabi E, Fantone J C. The selectins: insight into selectin-induced intracellular signaling in leukocytes. Immunol Res 1996. (In press.)

117 Katsuda S, Okada Y, Okada Y, Imai K, Nakanishi I. Matrix metalloproteinase-9 (92-kd gelatinase/type IV collagenase equals gelatinase B) can degrade arterial elastin. Am J Pathol 1994; 145: 1208-1218.

118 Murphy G, Docherty AJ . The matrix metalloproteinases and their inhibitors. Am J Respir Cell Mol Biol 1992; 7: 120-125.

119 Pereira HA. CAP37, a neutrophil-derived multifunctional inflammatory mediator. J Leukoc Biol 1995; 57: 805-812.

120 Brock J. Lactoferrin: a multifunctional immunoregulatory protein? Immunol Today 995; 16: 417-419.

121 Luscinskas FW, Lawler J . Integrins as dynamic regulators of vascular function. FASEB J 1994; 8: 929-938.

122 Crockett-Torabi E, Sullenbarger B, Smith CW, Fantone J . Activation of human neutrophil through L-selectin and mac-1 molecules. J Immunol 1995; 154: 2291-2302.

123 Rosales C, J uliano RL. Signal transduction by cell adhesion receptors in leukocytes. J Leukoc Biol 1995; 57: 189-198.

124 Gorski A. The role of cell adhesion molecules in immunopathology. Immunol Today 1994; 15: 251-255.

125 Albelda SM, Smith CW, Ward PA. Adhesion molecules and inflammatory injury. FASEB J 1994; 8: 504-512.

126 Noris M, Remuzzi G. New insights into circulating cellendothelium interactions and their significance for glomerular pathophysiology. Am J Kidney Dis 1995; 26: $541-548$.

127 Till GO, Lee S, Mulligan MS et al. Adhesion molecules in experimental phacoanaphylactic endophthalmitis. Invest Ophthalmol Vis Sci 1992; 33: 3417-3423.

128 Farhood A, McGuire GM, Manning AM, Miyasaka M, Smith $\mathrm{CW}$, J aeschke $\mathrm{H}$. Intercellular adhesion molecule 1 (ICAM-1) expression and its role in neutrophil-induced ischemia-reperfusion injury in rat liver. J Leuk Biol 1995; 57: 368-374.

129 Han KT, Sharar SR, Phillips ML, Harlan J M, Winn RK. Sialyl Lewis $X$ oligosaccharide reduces ischemia-reperfusion injury in the rabbit ear. J Immunol 1995; 155: 4011-4015.

130 Barnard J W, Biro MC, Lo SK et al. Neutrophil inhibitory factor prevents neutrophil-dependent lung injury. J Immunol 1995; 155: 4876-4881.

131 Cronstein BN, Weissmann G. Targets for antiinflammatory drugs. Annu Rev Pharmacol Toxicol 1995; 35: 449-462. 